\title{
Development of a Dissolution Method to Compare Tablet Formulations Containing Valsartan/Amlodipine
}

\author{
Abdel Naser Zaid ${ }^{1,}{ }^{*}$, Aiman Qaddomi², Mashhour Ghanem², Lina Shehadeh², \\ Murad Abualhasan ${ }^{1}$, Salam Natur ${ }^{2}$, and Saed Khammash ${ }^{1}$ \\ 1 Department of Pharmacy, An-Najah National University, P.O. Box 7, Nablus, Palestine \\ 2 Pharmacare Ltd. Beitunia, P.O. Box 677, Ramallah, Palestine
}

e-mail:anzaid@najah.edu zaid_n52@hotmail.com

\section{ABSTRACT}

Dissolution profiles were developed in three different $\mathrm{pH}$ media for the evaluation of valsartan/amlodipine (VS/AM) release from tablets. The selection of the most appropriate dissolution method was based on the calculated similarity $\left(f_{2}\right)$ and dissimilarity $\left(f_{1}\right)$ values. A new HPLC method was developed to quantify VS/AM in tablets. The method was validated in accordance with international guidelines and showed acceptable linearity, accuracy, precision, and selectivity. The system suitability results are within the acceptance criteria. The dissolution method (pH 6.8 phosphate buffer) was selected because it showed the highest $f_{2}$ and the lowest $f_{1}$ values for VS and AM among the other tested dissolution media. This method could be used for in vitro quality control and for performing in vitro-in vivo correlation (IVIVC) during the development of new generic tablets.

KEYWORDS: Similarity factor; HPLC; tablet; dissolution.

\section{INTRODUCTION}

$\mathrm{V}$ alsartan (VS), 3-methyl-2-[pentanoyl-[[4-[2-(2Htetrazol-5-yl) phenyl]phenyl]methyl]amino]-butanoic acid, is a nonpeptide, orally active, and specific angiotensin II antagonist acting on the angiotensin II type $1\left(A T_{1}\right)$ receptor subtype present in many tissues such as vascular smooth muscle and the adrenal gland (1). A placebo-controlled trial found VS to be both safe and effective for the treatment of hypertension (2), and other studies (3-5) have shown that VS is as effective as enalapril, lisinopril, and amlodipine in the treatment of mild to moderate hypertension. According to the Biopharmaceutics Classification System (BCS), VS is a Class III drug with low permeability, poor metabolism, and high solubility (6).

Amlodipine (AM) is (RS)-3-ethyl 5-methyl 2-[(2-aminoethoxy) methyl]-4-(2-chlorophenyl)-6-methyl-1,4-dihydropyridine-3,5-dicarboxylate. It is a dihydropyridine calcium channel blocker (CCB) used in the treatment of hypertension and is well-absorbed (bioavailability of $64-80 \%$ ) with no food effect after oral administration. The maximum plasma level is reached within 6-8 $\mathrm{h}$. The elimination phase occurs biexponentially with a long terminal half-life of 30-50 h. AM is extensively bound to plasma proteins (94-98\%) and is metabolized in the liver by CYP3A4 (7-9). It is classified as either BCS Class I or Class III and has high solubility, but its measured permeability is low (10). The relevant physicochemical properties for both agents are included in Table 1.

${ }^{*}$ Corresponding author.
Table 1. Physicochemical Properties of Valsartan and Amlodipine

\begin{tabular}{|l|c|c|}
\hline Property & Valsartan & Amlodipine \\
\hline BCS Class & II & I or III \\
\hline LogP & 1.5 & 3 \\
\hline Solubility (mg/L) & 16,800 & 75.3 \\
\hline pKa (25 \pm C) & 3.9 & 8.6 \\
\hline
\end{tabular}

A combination of drugs from two different classes can provide greater therapeutic response than a double dose of a single drug (2). The combination of a CCB and an $A T_{1}$ receptor antagonist is one of the most commonly prescribed drugs for hypertension. This formulation provides improved control of blood pressure with reduced cardiovascular and renal risk and minimal adverse effects. Exforge is the first commercially available combination of these drug classes as a fixed-dose regimen containing 5 or $10 \mathrm{mg} \mathrm{AM}$ and 160 or $320 \mathrm{mg}$ VS $(7,9,11)$. The present work reports the development and validation of a reversed-phase HPLC method for the estimation of VS/AM in tablets and the development of a validated method for the dissolution of these tablets. The inactive ingredients in Exforge (12) include colloidal silicon dioxide (glidant), crospovidone (disintegrant), magnesium stearate (lubricant), and microcrystalline cellulose (filler and disintegrant). The film coating contains hypromellose, iron oxides, polyethylene glycol, talc, and titanium 
dioxide. Other commercially available combination drugs, such as Valzepine, contain the same excipients in varying percentages. In the process of developing a new generic formulation for a marketed drug, the formulator tries to adhere to the same excipients used in the brand product to minimize any unexpected issues with stability. Additionally, the formulator attempts to find the level of excipients that minimizes in vivo release differences. The manufacturing process for the two products could be different because the original manufacturer does not make the details of the production process publicly available. Accordingly, a dissolution method should be able to discriminate between the generic product and the original brand. The aim of this study was to develop a dissolution method that has the ability to discriminate between the release profiles of the active ingredients upon changes in the formulation.

\section{EXPERIMENTAL}

\section{Materials}

Valzepine (batch number RD-03110) was supplied by Pharmacare PLC, Ramallah, Palestine. VS and AM Besylate USP Reference Standards were used to prepare a working standard solution. Exforge (AM 5 mg/VS 160 $\mathrm{mg}$ ), manufactured by Novartis Pharmaceuticals Corp., Suffern, NY, was used in this study. All the excipients used in the development of formulations were obtained from reliable commercial sources. Acetonitrile (HPLC grade), methanol (HPLC grade), potassium dihydrogen phosphate, glacial acetic acid, triethylamine, and phosphoric acid were all supplied by Merck (Darmstadt, Germany). HPLC grade water was obtained by reverse osmosis.

\section{Instrumentation}

A reversed-phase HPLC system (Merck-Hitachi, Lachrom Elite HPLC system, Japan) consisting of an autosampler Model L-7200, an interface Model D-7000, a photodiode array detector Model L-7450 A, and pump L-7100 was used. An Elma ultrasonic water bath, Millipore filtration assembly, and an electronic balance (Precisa 205 ASCS) were used. The formulated tablets were compressed by a Manesty tablet press (type D3B). Dissolution was carried out according to FDA guidelines using an Erweka apparatus (Erweka ZT-2, Heusenstamn, Germany).

\section{Methodology}

Formulations and Evaluation of Core Tablets

AM/VS tablet cores were prepared using a dry granulation method for compaction. The tablet core was composed of Avicel pH 101, crospovidone, Aerosil 200, and magnesium stearate. The core tablets were used to assess the dissolution profiles (13).

\section{Chromatographic Conditions}

Triethylamine buffer was prepared by mixing $3.5 \mathrm{~mL}$ of triethylamine with $450 \mathrm{~mL}$ of water and then adjusting the $\mathrm{pH}$ to $3.0 \pm 0.1$ with phosphoric acid. This was brought to volume in a $500-\mathrm{mL}$ flask and mixed well. The mobile phase consisted of solution $A$ (methanol/acetonitrile/ buffer [175:75:250; v/v/v]) and solution B (water/ acetonitrile/glacial acetic acid [300:700:1; v/v/v]) at a ratio of 1:1. HPLC was performed using an Inertsil ODS3V RP18e column $(250 \mathrm{~mm} \times 4.6 \mathrm{~mm}, 5-\mu \mathrm{m})$, a flow rate of $1.0 \mathrm{~mL} / \mathrm{min}$, a column temperature of $20^{\circ} \mathrm{C}$, and an injection volume of $20 \mu \mathrm{L}$. The UV detector wavelength $(\lambda)$ was $220 \mathrm{~nm}$, and the run time was $14 \mathrm{~min}$.

\section{Preparation of Working Solutions}

To prepare the stock standard solution, $19.3 \mathrm{mg}$ of AM besylate and $222.2 \mathrm{mg}$ of VS were dissolved in a 100$\mathrm{mL}$ volumetric flask and brought to volume with water/ acetonitrile (1:1). The working standard solutions were prepared by transferring $4 \mathrm{~mL}$ of stock standard solution to a $100-\mathrm{mL}$ volumetric flask and bringing to volume with the dissolution medium.

The samples were prepared by dissolving one tablet ( 5 $\mathrm{mg} \mathrm{AM} / 160 \mathrm{mg} V \mathrm{~S}$ ) in $900 \mathrm{~mL}$ of the dissolution medium, followed by filtration, and the filtrate was labeled and used as the sample solution.

\section{Method Validation and Degradation Studies}

The method was validated in accordance with the FDA and ICH guidelines using the parameters of system suitability, specificity, linearity, range, accuracy, precision, and ruggedness/robustness. System suitability was evaluated by injecting six replicates of the standard solutions and analyzing the resulting peaks of both active ingredients for peak area, tailing factor, resolution, number of theoretical plates, and capacity factor. To test selectivity, standard and sample test solutions of AM and VS were injected at the same wavelength, and the peaks were checked for retention time and any interference. Linearity and range of the method were evaluated by making ten separate injections in the range of $60-140 \%$.

Accuracy and precision were established by the analysis of three replicates of three concentrations near the test concentration $(80 \%, 100 \%$, and $120 \%)$; percentage recovery and \%RSD were calculated for each of the replicate samples.

The ruggedness/robustness of the method was determined by performing the same analysis with minor modifications of the method including altering the mobile phase $\mathrm{pH}$, detection wavelength, flow rate, elapsed assay 
time, and different analysts. Precision was determined by repeatability and intermediate precision. The repeatability test was performed via the determination of six homogeneous sample solutions. The \%RSD for the assay of the two active ingredients was then calculated. The acceptable limit of the \%RSD of assay results was set as less than $2.0 \%$. The accuracy was performed by injecting three different concentrations, and the percent recovery was then calculated for each component.

\section{Dissolution Test}

Twelve tablets of each product were selected for the dissolution tests. The dissolution test was carried out using USP Apparatus 2 (paddle). The volume of the dissolution medium was $900 \mathrm{~mL}$, and the rotation speed was set to $50 \mathrm{rpm}$. The dissolution media used were USP pH 6.8 phosphate buffer (13), pH 4.5 phosphate buffer, and 0.1 $\mathrm{N} \mathrm{HCl}$. The testing was performed at time intervals of 0 , $5,10,15,20$, and $30 \mathrm{~min}$. Each sample aliquot $(10 \mathrm{~mL})$ was withdrawn and replaced with an equal volume of fresh medium to maintain a constant total volume. Aliquots were filtered and analyzed using the validated HPLC method. Selection of a suitable dissolution method was based on the values of the calculated similarity factor $\left(f_{2}\right)$ and dissimilarity factor $\left(f_{1}\right)$ for the above selected three media. Values for $f_{1}$ and $f_{2}$ were calculated using eq 1 and 2 , respectively. The $f_{2}$ factor measures the closeness between two profiles, and $f_{1}$ measures the difference between two profiles:

$$
\begin{array}{r}
f_{1}=\left\{\left[\sum_{t=1}^{n}\left|R_{t}-T_{t}\right|\right] /\left[\sum_{t=1}^{n} R_{t}\right]\right\} \times 100 \\
f_{2}=50 \cdot \log \left\{\left[1+\frac{1}{n} \sum_{t=1}^{n}\left(R_{t}-T_{t}\right)^{2}\right]^{-0.5} \times 100\right\}
\end{array}
$$

where $R_{\mathrm{t}}$ and $T_{\mathrm{t}}$ are the percentages of drug dissolved at each time point for the reference and test products, respectively. An $f_{1}$ value greater than 15 indicates significant dissimilarity, and an $f_{2}$ value greater than 50 indicates significant similarity (14-16).

\section{RESULTS AND DISCUSSION \\ Dissolution Test Development in Three Different pH Media}

First, the dissolution test for the VS and AM formulated tablets was performed in $\mathrm{pH} 6.8$ phosphate buffer. The $f_{2}$ and $f_{1}$ values for these active ingredients were calculated. The results for VS revealed $f_{2}$ and $f_{1}$ values of 59 of 3 , respectively (Figure 1 and Table 2).
Table 2. Summary of $f_{2}$ and $f_{1}$ for VS and AM in Dissolution Media

\begin{tabular}{|l|c|c|c|c|c|c|}
\hline \multirow{2}{*}{} & \multicolumn{3}{|c|}{ VS } & \multicolumn{3}{c|}{ AM } \\
\cline { 2 - 7 } & \multicolumn{3}{|c|}{ Dissolution Medium } & \multicolumn{3}{c|}{ Dissolution Medium } \\
\cline { 2 - 7 } & $0.1 \mathrm{~N} \mathrm{HCl}$ & $\begin{array}{c}\text { pH 4.5 } \\
\text { phosphate } \\
\text { buffer }\end{array}$ & $\begin{array}{c}\text { pH } 6.8 \\
\text { phosphate } \\
\text { buffer }\end{array}$ & $0.1 \mathrm{~N} \mathrm{HCl}$ & $\begin{array}{c}\text { pH 4.5 } \\
\text { phosphate } \\
\text { buffer }\end{array}$ & $\begin{array}{c}\text { pH } 6.8 \\
\text { phosphate } \\
\text { buffer }\end{array}$ \\
\hline$f_{2}$ & 65 & 71 & 59 & 56 & 74 & 68 \\
\hline$f_{1}$ & 15 & 7 & 3 & 9 & 8 & 4 \\
\hline
\end{tabular}

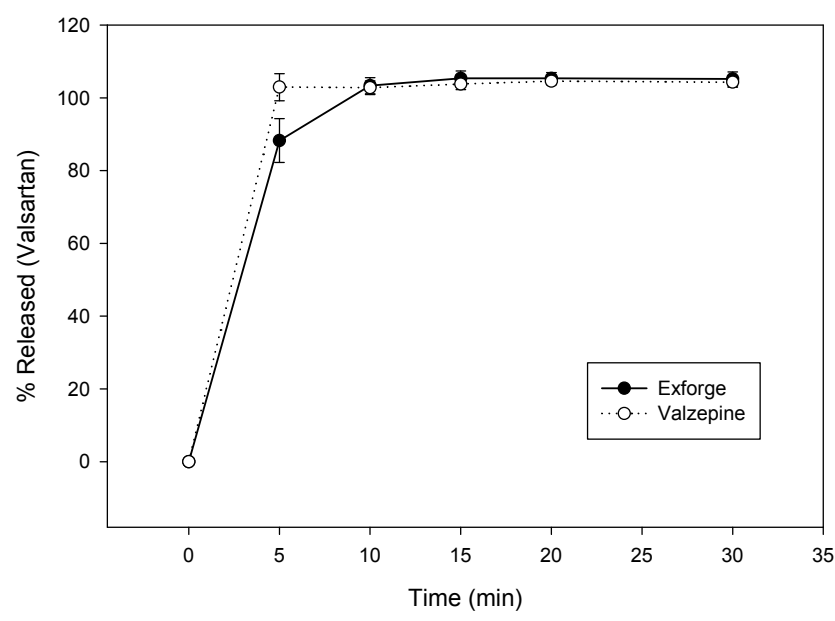

Figure 1. Dissolution profiles of valsartan in Exforge (160/5) and Valzapine (160/5) tablets in pH 6.8 phosphate buffer.

The $f_{2}$ and $f_{1}$ values for AM were 68 and 4 , respectively (Figure 2 and Table 2).

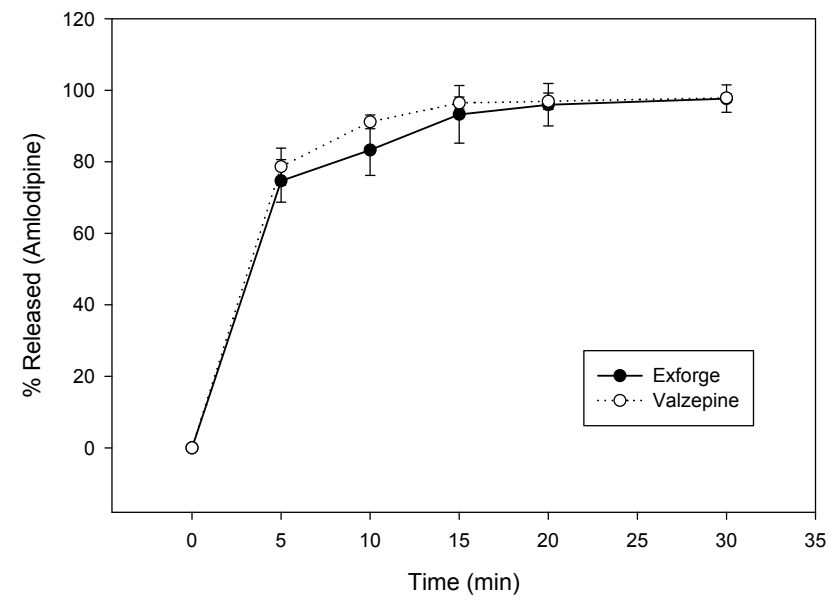

Figure 2. Dissolution profiles of amlodipine in Exforge (160/5) and Valzapine (160/5) tablets in pH 6.8 phosphate buffer.

Dissolution testing of the commercial tablets (Valzepine) was also performed in $\mathrm{pH} 4.5$ phosphate buffer. The $f_{2}$ 
and $f_{1}$ values for VS were 71 and 7 , respectively (Figure 3 and Table 2), while $f_{2}$ and $f_{1}$ for AM were 74 and 8, respectively (Figure 4 and Table 2 ).

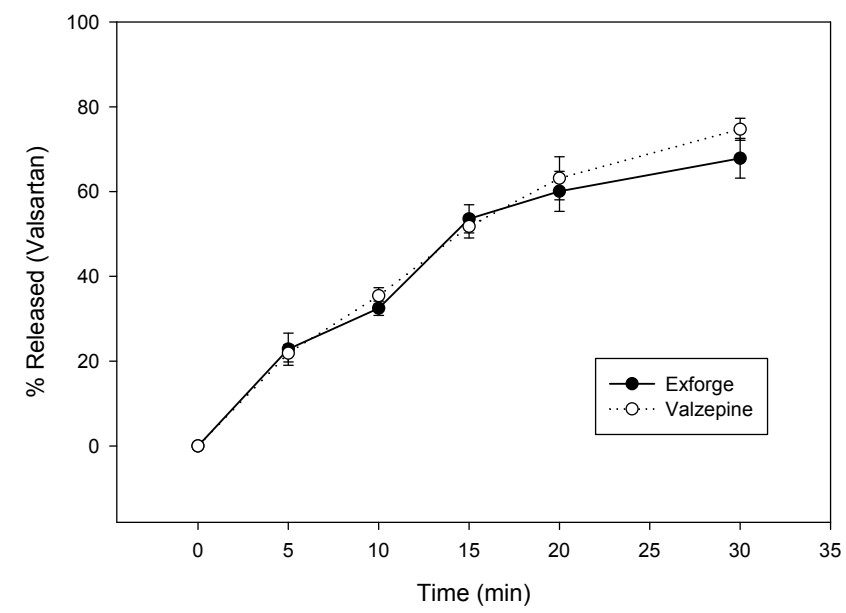

Figure 3. Dissolution profiles of valsartan in Exforge (160/5) and Valzapine (160/5) tablets in pH 4.5 phosphate buffer.

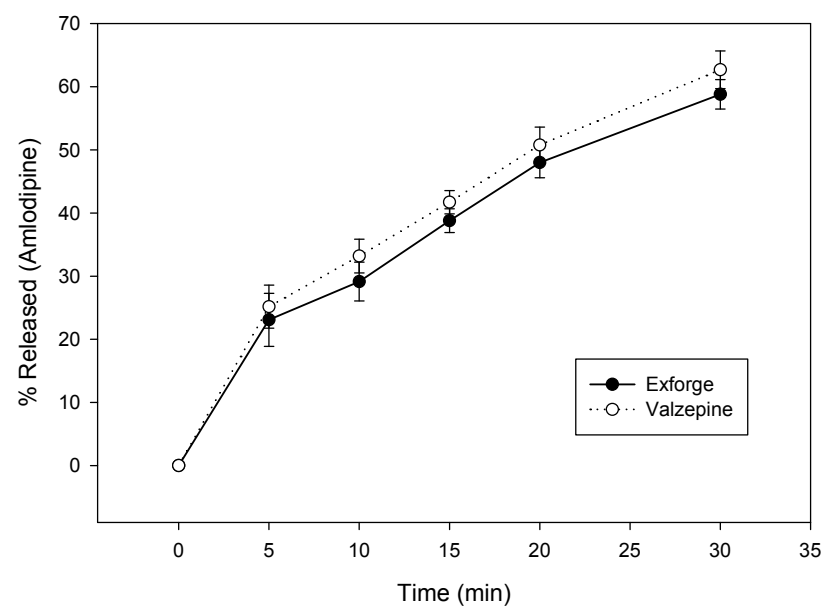

Figure 4. Dissolution profiles of amlodipine in Exforge (160/5 and Valzapine (160/5) tablets in pH 4.5 phosphate buffer.

Dissolution was also performed with $0.1 \mathrm{~N} \mathrm{HCl}$, and the results show $f_{2}$ and $f_{1}$ values for VS of 65 and 15 , respectively, and $f_{2}$ and $f_{1}$ for $A M$ of 56 and 9 , respectively. A summary of the dissolution results for VS/AM brand and generic formulation tablets in $0.1 \mathrm{~N} \mathrm{HCl}$ is shown in Table 2.

Reference compendia and guidelines of FDA, USP, WHO, and $P h$. Eur. recommend the use of a rotating paddle dissolution apparatus between 50 to $100 \mathrm{rpm}$ with a volume up to $1000 \mathrm{~mL}$ along with surfactant to provide sink condition for insoluble drug products (17). The dissolution test was developed according to international guidelines $(16,18)$. Tablets of the branded drug and the generic drug product were evaluated. The assay of active ingredients in the pharmaceutical products was performed using a validated HPLC analytical method. The use of $900 \mathrm{~mL}$ of $\mathrm{pH} 6.8$ phosphate buffer at $37 \pm 0.5^{\circ} \mathrm{C}$ and a paddle speed of $50 \pm 2 \mathrm{rpm}$ was satisfactory due to the above-mentioned differences in $f_{1}$ and release time.

A simple model-independent approach using $f_{1}$ and $f_{2}$ to compare dissolution profiles was used $(16,19)$. The dissimilarity factor $\left(f_{1}\right)$ calculates the percent difference between the two curves at each time point, and it measures the relative error between the two curves. The similarity factor $\left(f_{2}\right)$ is the measurement of the similarity in the percent dissolution between the two curves. When $f_{1}$ is close to 0 and $f_{2}$ is close to 100 , the method is considered discriminatory and the curves are considered similar. Usually, $f_{1}$ values in the range of $0-15$ and $f_{2}$ values greater than 50 and less than 100 ensure the equivalence of the two curves according to the FDA guidelines. Accordingly, the discriminatory dissolution method is a very important in vitro test used during the development of a generic solid dosage form.

Because there is no pharmacopeial dissolution method specified for VS/AM tablets in the literature, an attempt was made to develop a modified version of the method recommended by the FDA (20). The method should be able to discriminate between the release patterns of the APIs upon formulation changes. Accordingly, three dissolution media were tested: $0.1 \mathrm{~N} \mathrm{HCl}$ and phosphate buffer at $\mathrm{pH} 4.5$ and $\mathrm{pH} 6.8$. The use of $0.1 \mathrm{~N} \mathrm{HCl}$ dissolution medium was excluded from our study because it showed the lowest $f_{2}$ and highest $f_{1}$ values among the other dissolution media. The dissolution conditions of $900 \mathrm{~mL}$ of phosphate buffer (pH 4.5 and 6.8) at $37 \pm$ $0.5^{\circ} \mathrm{C}$ and a paddle speed of $50 \pm 2 \mathrm{rpm}$ showed nearly similar $f_{2}$ values, but the $\mathrm{pH} 6.8$ buffer showed the lowest $f_{1}$ values. Moreover, the time for $85 \%$ release of the APIs in $\mathrm{pH} 6.8$ phosphate buffer was shorter than that in $\mathrm{pH}$ 4.5 phosphate buffer. In fact, at pH 6.8, more than $85 \%$ of both VS and AM was released within 10 min (Figures 1 and 2). This would provide a practical advantage over conducting the test at $\mathrm{pH} 4.5$. This time-saving advantage is important in the pharmaceutical industry because a shorter working time can mean higher productivity and work effectiveness. Accordingly, changes in the formulation at the level of lubricant and disintegrant were carried out to measure the discriminatory power 
of the method. As shown in Figures 5 and 6, using this dissolution method and these conditions, we were able to predict a slower rate of release of VS and AM when increasing amounts of magnesium stearate were included in the formulation. Table 3 shows the calculated values for $f_{2}$ and $f_{1}$ for three different formulations of AM/VS. These formulas contained $1 \%, 2 \%$, and $3 \%$ by weight of magnesium stearate. As expected, the release rate of the formulation with the highest level of lubricant was slower than the conventional formula (1\%). This difference is concluded from the low value of $f_{2}$ ( 49 and 40 for amlodipine and valsartan, respectively) and a high value for $f_{1}$ (13.81 and 19.4 for amlodipine and valsartan, respectively).

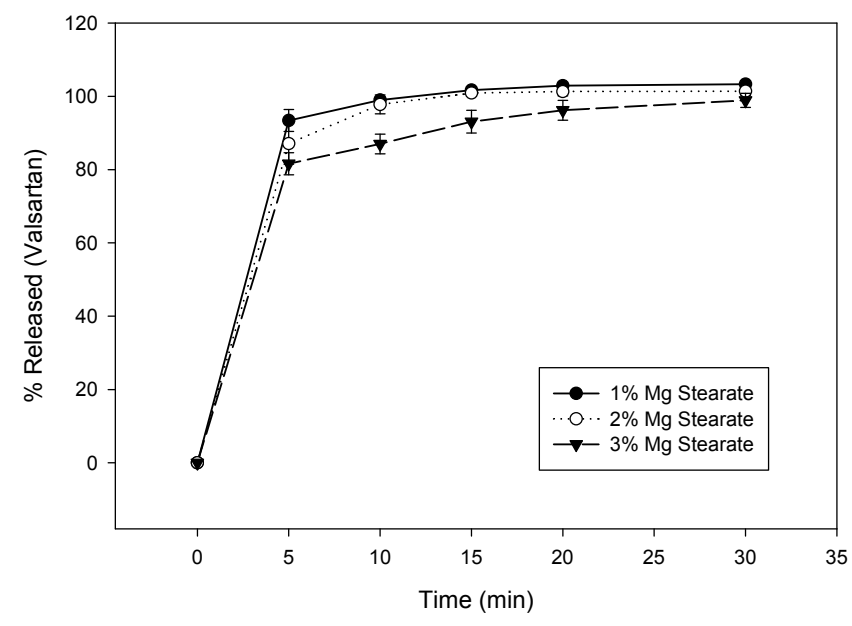

Figure 5. Dissolution profiles of valsartan from valsartan/ amlodipine tablets containing different percentages (of the master formula) of magnesium stearate.

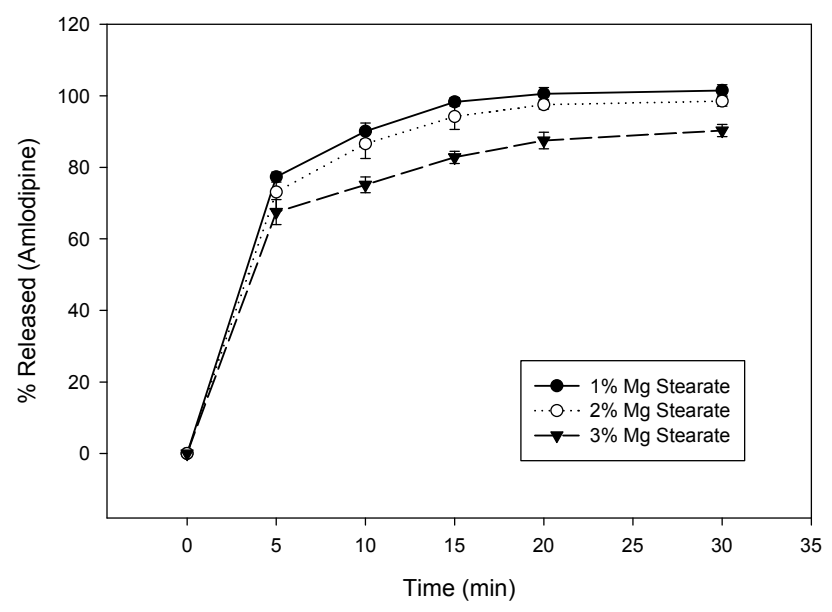

Figure 6. Dissolution profiles of amlodipine from valsartan/ amlodipine tablets containing different percentages (of the master formula) of magnesium stearate.
Table 3. Calculated Similarity $\left(f_{2}\right)$ and Dissimilarity $\left(f_{1}\right)$ for Three

Different Formulations of AM/VS Combination

\begin{tabular}{|l|c|c|c|c|}
\hline & \multicolumn{2}{|c|}{ Valsartan } & \multicolumn{2}{c|}{ Amlodipine } \\
\hline Comparison & $1 \%$ vs $2 \%$ & $1 \%$ vs $3 \%$ & $1 \%$ vs $2 \%$ & $1 \%$ vs $3 \%$ \\
\hline$f_{2}$ & 78.9 & 40 & 76 & 49 \\
\hline$f_{1}$ & 2.36 & 19.4 & 3.83 & 13.81 \\
\hline
\end{tabular}

It was expected that the new dissolution method would not detect any difference between the release profiles of the active ingredients. Additionally, when intentional modifications of the formula of the generic product were made, it was expected that these differences would be reflected in the dissolution profiles and the calculated $f_{1}$ and $f_{2}$ values. Indeed, the performance of this method was supported by an in vivo study that demonstrated that Exforge and Valzepine are bioequivalent (9).

\section{Dissolution Profiles for Different VS/AM Tablet Formulations}

Formulations Containing Different

Lubricant Concentrations

Three different VS/AM tablet formulations were prepared containing three levels of magnesium stearate $(1 \%, 2 \%$, and $3 \%$ ) to exhibit three release profiles: fast, intermediate, and slow, respectively. The dissolution profiles were obtained using the selected $\mathrm{pH} 6.8$ phosphate buffer as dissolution medium to test its discriminatory power. The $f_{2}$ and $f_{1}$ factors were then calculated (Figures 5 and 6 ).

The above results demonstrate that there was no apparent difference between the release profile for AM and VS at the $2 \%$ magnesium stearate formulation, indicating that this level of lubricant is tolerated (Table 4).

\section{Formulations Containing Different \\ Disintegrant Concentrations}

Another type of excipient change was carried out to test the ability of our dissolution method to discriminate between differences in formulation composition. This change was in the level of disintegrant (crospovidone). Three tablet formulations containing three increasing levels of the disintegrant $(45,60$, and $75 \mathrm{mg})$ were prepared. The dissolution profiles for VS and AM for these new formulas are shown in Figures 7 and 8, respectively. For both active ingredients, the change in disintegrant concentration resulted in a change in the dissolution profiles. A sizable difference is observed between disintegrant levels of 45 $\mathrm{mg}$ and $60 \mathrm{mg}$, but the difference is almost negligible when the level is increased to $75 \mathrm{mg}$. This observation is expected because the disintegration time would not be reduced further after the addition of a certain amount of disintegrant. 


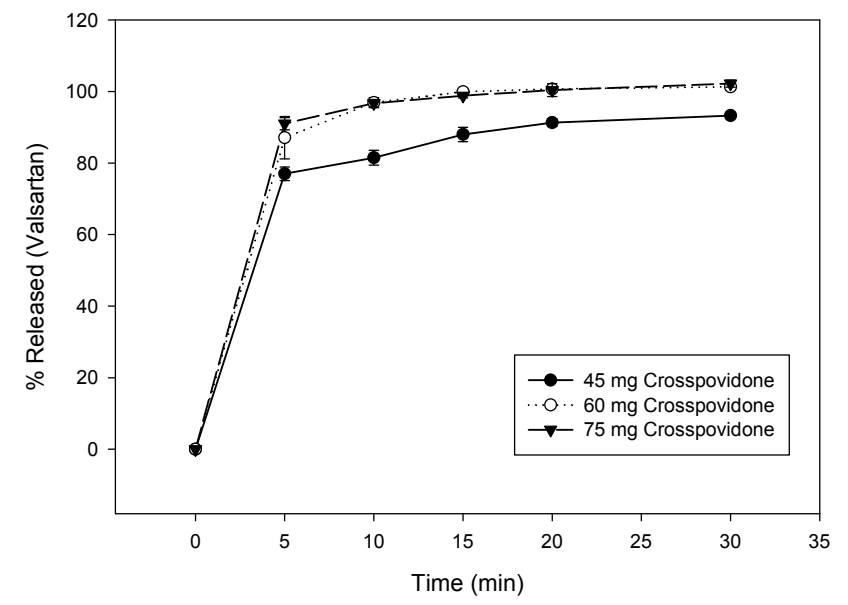

Figure 7. Dissolution profiles of valsartan from valsartan/ amlodipine tablets containing different percentages (of the master formula) of crospovidone.

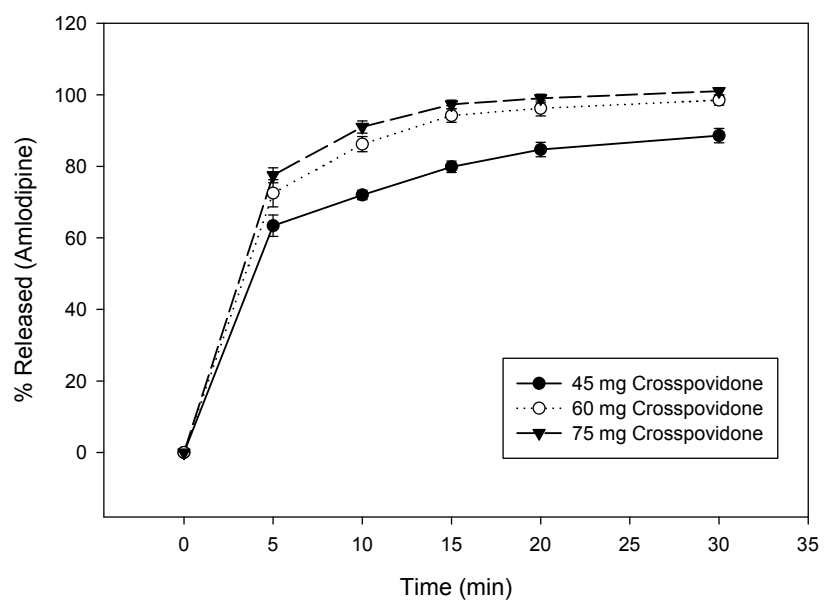

Figure 8. Dissolution profiles of amlodipine from valsartan/ amlodipine tablets containing different percentages (of the master formula) of crospovidone.

\section{Method Validation}

Several methods are available in the literature to measure the concentration of VS and $\mathrm{AM}$ in individual and combined products (21-23). The method was validated for parameters like system suitability, selectivity, linearity, range, precision, accuracy, and robustness. The method was validated to quantify VS/AM drug release in the dissolution tests as per ICH guidelines (18).

The system suitability results for the combined solution of AM and VS are summarized in Table 4. The method showed no interferences at the retention times of AM and VS. This demonstrates that the proposed method is a selective method for the quantification of the active ingredients in AM/VS tablets. To determine linearity and range, solution concentrations in the range of $50-160 \%$ of the final assay concentrations for AM and VS were prepared. Then standard curves for AM and VS were constructed by plotting peak area versus drug concentration. The method showed good linearity in this range with the coefficient of regression $R$ values for AM and VS almost equal to 1.

Precision was determined by a repeatability test with the same analytical equipment on the same day and by the same analyst. The \%RSD for the assay results of the two active ingredients showed values of $1.03 \%$ and $1.12 \%$ for AM and VS, respectively, which are within the acceptable limit of $2.0 \%$. The accuracy for VS and for AM was determined at three different concentrations, and the percent recovery was then calculated for each ingredient. All results were within the acceptable range as shown in Table 4. Lastly, the robustness parameters and results are illustrated in Table 4.

\begin{tabular}{|c|c|c|c|}
\hline \multicolumn{4}{|c|}{ System Suitability } \\
\hline \multicolumn{2}{|c|}{ Parameters } & \multicolumn{2}{|c|}{ Acceptance Criteria } \\
\hline \multicolumn{2}{|l|}{ Resolution (R) } & \multicolumn{2}{|c|}{$\geq 2$} \\
\hline \multicolumn{2}{|l|}{ Tailing ( $\mathrm{T}$ ) } & \multicolumn{2}{|c|}{$\leq 2.0$} \\
\hline \multicolumn{2}{|c|}{ Theoretical plates $(\mathrm{N})$} & \multicolumn{2}{|c|}{$\geq 2000$ plates } \\
\hline \multicolumn{2}{|l|}{ Capacity factor } & \multicolumn{2}{|c|}{$\geq 2$} \\
\hline \multicolumn{4}{|c|}{ Accuracy } \\
\hline $\begin{array}{c}\% \text { Original } \\
\text { Concentration }\end{array}$ & $\begin{array}{c}\text { AM Recovery } \\
\text { (\%) }\end{array}$ & $\begin{array}{c}\text { VS Recovery } \\
(\%)\end{array}$ & $\begin{array}{l}\text { Acceptance } \\
\text { (\%) }\end{array}$ \\
\hline 50 & 99.97 & 100.67 & \multirow{3}{*}{$\begin{array}{l}\text { Recovery limit: } \\
98.0-102.0 \%\end{array}$} \\
\hline 100 & 101.00 & 100.02 & \\
\hline 160 & 100.58 & 100.52 & \\
\hline \multicolumn{4}{|c|}{ Robustness Parameters } \\
\hline \multicolumn{2}{|c|}{ Parameter } & \multicolumn{2}{|c|}{ Condition Checked } \\
\hline \multicolumn{2}{|l|}{ Buffer $\mathrm{pH}$ values } & \multicolumn{2}{|l|}{$2.8,3.0$, and 3.2} \\
\hline \multicolumn{2}{|l|}{ Columns } & \multicolumn{2}{|c|}{$\begin{array}{l}\text { Three different columns of the } \\
\text { same stationary phase }\end{array}$} \\
\hline \multicolumn{2}{|c|}{ Mobile phase flow rate } & \multicolumn{2}{|c|}{$\begin{array}{l}0.8 \mathrm{~mL} / \mathrm{min}, 1.0 \mathrm{~mL} / \mathrm{min} \text {, and } 1.2 \\
\mathrm{~mL} / \mathrm{min}\end{array}$} \\
\hline \multicolumn{2}{|c|}{ Mobile phase composition (A/B) } & \multicolumn{2}{|c|}{$95: 105,100: 100,105: 95$} \\
\hline \multicolumn{2}{|c|}{ Column temperatures } & \multicolumn{2}{|c|}{$17^{\circ} \mathrm{C}, 20^{\circ} \mathrm{C}, 23^{\circ} \mathrm{C}$} \\
\hline
\end{tabular}

\section{CONCLUSION}

The new HPLC method shows several advantages over other known methods for the analysis of VS/AM in tablets. It is a single, economical method that can be used to assay the two ingredients. The method was validated in compliance with the $\mathrm{ICH}$ guidelines showing linearity, accuracy, precision, selectivity, stability, and 
system suitability. The proposed dissolution method $(\mathrm{pH}$ 6.8 phosphate buffer) can be used as an in vitro quality control test to check any batch-to-batch variability in product release. It can also be used to carry out in vitroin vivo correlation during the development of new generic tablets because the data and graph show the highest $f_{2}$ and the lowest $f_{1}$ values of VS and AM of the tested dissolution media.

\section{CONFLICT OF INTEREST}

No conflict of interest has been declared by the authors.

\section{REFERENCES}

1. Weber, M. A. Review: Angiotensin II receptor blockers and cardiovascular outcomes: what does the future hold? J. ReninAngiotensin-Aldosterone Syst. 2003, 4 (2), 62-73. DOI: 10.3317/ jraas.2003.015.

2. Oparil, S.; Dyke, S.; Harris, F.; Kief, J.; James, D.; Hester, A.; Fitzsimmons, $\mathrm{S}$. The efficacy and safety of valsartan compared with placebo in the treatment of patients with essential hypertension. Clin. Ther. 1996, 18 (5), 797-810. DOI: 10.1016/ S0149-2918(96)80040-3.

3. Black, H. R.; Graff, A.; Shute, D.; Stoltz, R.; Ruff, D.; Levine, J.; Shi, Y.; Mallows, $S$. Valsartan, a new angiotensin II antagonist for the treatment of essential hypertension: efficacy, tolerability and safety compared to an angiotensin-converting enzyme inhibitor, lisinopril. J. Hum. Hypertens. 1997, 11 (8), 483-489. DOI: 10.1038/sj.jhh.1000482.

4. Corea, L.; Cardoni, O.; Fogari, R.; Innocenti, P.; Porcellati, C.; Provvidenza, M.; Meilenbrock, S.; Sullivan, J.; Bodin, F. Valsartan, a new angiotensin II antagonist for the treatment of essential hypertension: A comparative study of the efficacy and safety against amlodipine. Clin. Pharmacol. Ther. 1996, 60 (3), 341346. DOI: 10.1016/S0009-9236(96)90061-2.

5. Holwerda, N. J.; Fogari, R.; Angeli, P.; Porcellati, C.; Hereng, C.; Oddou-Stock, P.; Heath, R.; Bodin, F. Valsartan, a new angiotensin II antagonist for the treatment of essential hypertension: efficacy and safety compared with placebo and enalapril. J. Hypertens. 1996, 14 (9), 1147-1151. DOI: 10.1097/00004872-19960900000016.

6. Siddiqui, N.; Husain, A.; Chaudhry, L.; Alam, M. S.; Mitra, M.; Bhasin, P. S. Pharmacological and Pharmaceutical Profile of Valsartan: A Review. J. Appl. Pharm. Sci. 2011, 1 (4), 12-19.

7. Krzesinski, J.-M.; Cohen, E. P. Exforge ${ }^{\circledR}$ (amlodipine/valsartan combination) in hypertension: the evidence of its therapeutic impact. Core Evidence 2009, 4, 1-11. DOI: 10.2147/CE.S6007.

8. Plosker, G. L.; Robinson, D. M. Amlodipine/Valsartan: Fixed-Dose Combination in Hypertension. Drugs 2008, 68 (3), 373-381. DOI: 10.2165/00003495-200868030-00008.

9. Zaid, A. N.; Natur, S.; Qaddomi, A.; Abualhasan, M.; Al-Ramahi, R.; Shraim, N.; Khammash, S.; Jaradat, N. Formulation and bioequivalence of two Valsartan/Amlodipine Immediate release tablets after a single oral administration. Pak. J. Pharm. Sci. 2014, $27(4), 755-762$.

10. Proposal to waive in vivo bioequivalence requirements for WHO Model List of Essential Medicines immediate release, solid oral dosage forms; Working document QAS/04.109/ Rev 1; World Health Organization: Geneva, 2006. http://www. who.int/medicines/services/expertcommittees/pharmprep/ QAS04_109Rev1_Waive_invivo_bioequiv.pdf (accessed June 27, 2015).

11. Rubio-Guerra, A. F.; Castro-Serna, D.; Elizalde-Barrera, C. I.; Ramos-Brizuela, L. M., Current concepts in combination therapy for the treatment of hypertension: combined calcium channel blockers and RAAS inhibitors. Integr. Blood Pressure Control 2009, 2, 55-62.

12. Exforge (Amlodipine and Valsartan) Tablets. RxList Web site. http://www.rxlist.com/exforge-drug.htm (accessed May 29, 2015).

13. The United States Pharmacopeia and National Formulary USP 33-NF 28; The United States Pharmacopeial Convention, Inc.: Rockville, MD, 2010.

14. Emami, J. In Vitro-In Vivo Correlation: From Theory To Applications. J. Pharm. Pharm. Sci. 2006, 9 (2), 169-189.

15. Fortunato, D. Dissolution Method Development for Immediate Release Solid Oral Dosage Forms. Dissolution Technol. 2005, 12 (3), 12-14. DOI: 10.14227/DT120305P11.

16. Gupta, A.; Gaud, R. S.; Ganga, S. Development of Discriminating Dissolution Method for an Insoluble Drug: Nisoldipine. Int. J. PharmTech Res. 2010, 2 (1), 931-939.

17. Brown, C. K.; Chokshi, H. P.; Nickerson, B.; Reed, R. A.; Rohrs, B. R.; Shah, P. A. Acceptable Analytical Practices for Dissolution Testing of Poorly Soluble Compounds. Pharm. Technol. 2004, 28 (12), 56-65.

18. International Conference on Harmonisation of Technical Requirements for Registration of Pharmaceuticals for Human Use. Evaluation and Recommendation of Pharmacopoeial Texts for Use in the ICH Regions on Dissolution Test General Chapter, Q4B ANNEX 7(R2); ICH Harmonised Tripartite Guideline: Geneva, Switzerland, 2010.

19. Soni, T.; Nagda, C.; Gandhi, T.; Chotai, N. P. Development of Discriminating Method for Dissolution of Aceclofenac Marketed Formulations. Dissolution Technol. 2008, 15 (2), 31-35. DOI: 10.14227/DT150208P31.

20. Dissolution Methods Database. U.S. Food and Drug Administration Web site. http://www.accessdata.fda.gov/ scripts/cder/dissolution/dsp_SearchResults_Dissolutions. cfm?PrintAll=1 (accessed June 27, 2015).

21. Darwish, H. W.; Hassan, S. A.; Salem, M. Y.; El-Zeany, B. A., Comparative study between derivative spectrophotometry and multivariate calibration as analytical tools applied for the simultaneous quantitation of Amlodipine, Valsartan and Hydrochlorothiazide. Spectrochim. Acta, Part A 2013, 113, 215223. DOI: 10.1016/j.saa.2013.04.068.

22. Shentu, J.; Fu, L.; Zhou, H.; Hu, X. J.; Liu, J.; Chen, J.; Wu, G. Determination of amlodipine in human plasma using automated online solid-phase extraction HPLC-tandem mass spectrometry: Application to a bioequivalence study of Chinese volunteers. J. Pharm. Biomed. Anal. 2012, 70, 614-618. DOI: 10.1016/j. jpba.2012.06.014.

23. Zaid, A. N.; Cortesi, R.; Qaddomi, A.; Khammash, S. Formulation and Bioequivalence of Two Valsartan Tablets After a Single Oral Administration. Sci. Pharm. 2011, 79 (1), 123-135. DOI: 10.3797/scipharm.1009-01. 